\title{
La experiencia común
}

Recibido / Received 9 de noviembre de 2020

AUTORES / AUTHORS

- Aceptado / Acepted

Giuseppe Capograssi

19 de noviembre de 2020

EDITORIAL / PUBLISHING COMPANY

- Páginas / Pages

De la 377 a la 379

Madrid, Ediciones Encuentro, 2020, 231 pp.

- ISSN: 1885-365X

Desde fuera se presenta como un libro sobre filosofía del derecho. Pero La experiencia común no es solo un libro sobre los fundamentos filosóficos de las leyes. A lo largo de sus dos centenares de páginas, Giuseppe Capograssi propone un recorrido por las etapas de esa experiencia común en la que el individuo concreto, en su relación con los otros e inmerso en la dialéctica finitoinfinito, descubre la existencia del imperativo jurídico y del moral, que le llaman a llevar a cabo la acción hasta el final y a realizarse y cumplir el destino que le es propio: «La experiencia en su concreción se funda en la conciencia y en la voluntad que tiene el individuo de tener su propio camino y su propia meta y de deber recorrer aquel y llegar a esta» (Capograssi, 2020, p. 35).

Publicada en 1930, bajo el título original de Analisi dell'esperienza comune, ahora ve la luz en castellano en esta publicación de Ediciones Encuentro, traducida y editada por Ana Llano Torres (que introduce unos subtítulos adicionales que facilitan enormemente su lectura) y prologada por Miguel García Baró. En su estudio preliminar a La lucha por el individuo común, anónimo y estadístico. Textos escogidos de Giuseppe Capograssi (Llano Torres, 2016, pp. 9-72), la editora subrayó el valor de la obra que ahora reseñamos:

Consciente de la crisis que atraviesa el mundo contemporáneo, pero sin rastro de queja o lamento, sin pretensión alguna de huir al pasado o proyectarse en el futuro, Capograssi no pierde nunca de vista que la línea que separa el bien del mal atraviesa el corazón de cada uno (Llano Torres, 2016, p. 69).

No nos encontramos ante «una introducción al estudio de la experiencia común» (Capograssi, 2020, p. 45), como indica él mismo en las Premisas, sino más bien una guía hacia esta, un resumen de aquellas razones por las que la experiencia y la riqueza de la acción o de la vida ordinaria han de ser tenidas en cuenta e incluso amadas, en tanto que dependientes de las cosas y de una conciencia trascendental (Capograssi, 2020, pp. 45, 75).

Frente a lo abstracto de ciertos planteamientos, tanto en la filosofía como en otros campos del saber, Capograssi aboga por lo concreto, por el sentido práctico del individuo en relación con la realidad. «[E]l filosofar capograssiano nace de la vida», sostiene Llano Torres en la nota introductoria (Capograssi, 2020, p. 25). Esta vida se traduce en la conciencia de uno mismo y de aquello «que lo sobrepasa» (Capograssi, 2020, p. 32): en el vínculo con los semejantes, en la idea de Dios, en la libertad para elegir el bien o el mal, en la actitud hacia el sistema de normas, morales o 
jurídicas. Para ello, el jurista y filósofo italiano se sirve de su experiencia, valga la redundancia en este caso, tanto la que ha ido obteniendo en su trabajo como abogado y académico como aquella de la propia vida, en el choque con la realidad, empleando su terminología.

El ansia de cumplimiento a la que constantemente se refiere no ha de entenderse tampoco como individualismo o egoísmo, pues el amor propio no es sino amor a la vida, entendido como "voluntad de vivir, de existir, de sentir, de conocer y de unirse a la vida que hay en el universo, a todas las vidas que el conocimiento descubre» (Capograssi, 2020, p. 85). Sin embargo, este planteamiento que necesita de la acción se enfrenta a la tendencia del sujeto a anclarse en su inercia originaria, a la contradicción que produce cansancio del sujeto en movimiento. Pero ante esta ocasión de lucha claman las exigencias de su naturaleza, frente a la invitación a detenerse emerge la búsqueda de la satisfacción de la vida (Capograssi, 2020, pp. 106, 107). Es, pues, poner en juego la libertad:

O realizar la acción realmente y llevarla a término, o traicionar y falsificar la esencia misma de la acción en vez de llegar hasta el fondo. Esta elección tiene lugar en toda acción del sujeto: en toda acción, la voluntad se encuentra frente a la necesidad de escoger entre la verdad de toda la realidad y la verdad, la única verdad del sujeto. Aquí radica la indestructible libertad de la voluntad (Capograssi, 2020, p. 119).

Y como defensa de los asaltos del mal se erige la experiencia ética, en la que puede apoyarse la voluntad capaz de reconocerlo, identificarlo y elegir, en su lugar, la vida. En esa afirmación de la verdad pueden sostenerse la libertad y la voluntad para dar lugar a «una continua construcción de vida [...] una intensificación y multiplicación de vida» (Capograssi, 2020 , p. 131). La expresión de esa voluntad en su vertiente común es la formulación legislativa, la ley como garante de la realidad implícita en la acción que ha de ser determinación racional de sí misma en la materia concreta de lo real, y el Estado como realización universal de esta (Capograssi, 2020, pp. 164-166).

Por su parte, en el terreno de la ley moral - continuación de la ley jurídica- nos encontramos de nuevo con el problema de la acción, con el sujeto en la posición de seguir o no la ley ética, de obedecer o no al imperativo jurídico bajo el dilema, una vez más, de la acción: « ¿salvar o no salvar la acción, llevarla a término o dejarla a la mitad, hacer vivir los gérmenes de vida que esconde o destruirlos?» (Capograssi, 2020, p. 191). También de nuevo encontramos el mal jurídico, que no reside en la violación o inobservancia de las normas, sino en sustraerse al imperativo en lugar de tomar la experiencia jurídica en su plenitud.

Al publicarse El individuo sin individualidad (Capograssi, 2015), la editora se complacía en la posibilidad de que se cumpliera «el deseo escondido de aquel hombre humilde como pocos" de que alguno de sus trabajos fuera descubierto por los jóvenes entre los libros fuera de moda y acompañarles en el camino de la vida (Llano Torres, 2015, pp. 224-225) y, subrayando que la filosofía de la acción capograssiana es una lucha contra el mal y contra la disolución del yo, en la estación del nihilismo en el que nos ahogamos, nos instaba a los españoles a secundar el reclamo de Capograssi a conservar

la locura o la necedad de estar persuadidos de que cada uno de nosotros puede y por tanto debe transformar el mundo [...] La vieja Europa, en esa parte donquijotesca de ella, que constituye verdaderamente su grandeza, no ha sido sino esta locura [...] Mantengámonos fieles a esta locura (Llano, 2015, p. 256). 
Capograssi plantea el derecho como afirmación de la vida y la realidad en el campo de la acción, sin obviar que existe algo más profundo que esta: la exigencia de realizar la vida en su plenitud, que gracias al imperativo jurídico encuentra la protección para alcanzar su cumplimiento (Capograssi, 2020, p. 192, 193), no en la experiencia ética sino en una satisfacción ulterior: el cumplimiento en la vida absoluta y en la esperanza en Dios «¿Qué es, a fin de cuentas, la vida?» (Capograssi, 2020, p. 227).

\section{Bibliografía}

CAPOGRASSI, Giuseppe. (2020). La experiencia común. Madrid: Ediciones Encuentro.

CAPOGRASSI, Giuseppe. (2015). El individuo sin individualidad. Madrid: Ediciones Encuentro.

LLANO TORRES, Ana (2016). La lucha por el individuo común, anónimo y estadístico Textos escogidos de Giuseppe Capograssi. Madrid: Centro de Estudios Políticos y Constitucionales, pp. 9-72.

LLANO TORRES, Ana (2015). "A propósito de la edición en español de Incertezze sullindividuo de Capograssi». Rivista Internazionale di Filosofia del Diritto, 2, pp. 215-257.

Por la María Solano Conde

Universidad CEU San Pablo

@ msolanoconde@gmail.com iD 0000-0001-5910-5550 